\author{
Mediterranean BioMedical Journals \\ Integrative Journal of Medical Sciences \\ 2020, Volume 7, ID 198 \\ DOI: 10.15342/ijms.7.198
}

\title{
REVIEW
}

\section{Nutritional Considerations in COVID-19 Pandemic}

\author{
Yan Zhang (iD) \& Guoxun Chen (iD) \\ Department of Nutrition, University of Tennessee at Knoxville, Knoxville, Tennessee, USA
}

\begin{abstract}
In December 2019, a novel severe acute respiratory syndrome coronavirus (SARS-CoV-2) emerged in Wuhan, China, which is followed by the global pandemic of coronavirus disease (COVID-19). So far, COVID-19 is affecting the health and lives of millions of people and impacting economic dramatically in more than 180 countries worldwide. Since the outbreak of COVID-19, potential medical treatments and vaccines have been developed and tested by biotech and pharmaceutical companies. Nutrition is critical for prevent and recovery of diseases. Multiple nutrients have been considered as potential means to help in the combat against COVID-19. In addition, nutritional considerations are also important for people to maintain healthy when their daily dietary behaviors and physical activities are altered by COVID-19. Here, we tried to summarize potential medical treatments, vaccines, and important nutrients affecting outcomes of COVID-19 patients. In addition, we discussed the influences of dietary supplement and lifestyle for healthy and sensitive populations during the pandemic.
\end{abstract}

KEYWORDS: Coronavirus ; COVID-19 ; Vitamin C ; Vitamin D ; Vitamin A ; Hydroxychloroquine ; Nutrition

Correspondence: Guoxun Chen, Ph.D., 229 Jessie Harris Building, 1215 West Cumberland Avenue, Knoxville, Tennessee 37996, USA.gchen6@utk.edu

Copyright $(2020$ Yan Zhang \& Guoxun Chen. This is an open access article distributed under the Creative Commons Attribution 4.0 International, which permits unrestricted use, distribution, and reproduction in any medium, provided the original work is properly cited.

\section{INTRODUCTION}

As of 27 July, 2020, the World Health Organization reported that the number of people with Coronavirus Disease 2019 (COVID-19), a disease due to infection of severe acute respiratory syndrome coronavirus 2 (SARSCoV2) has reached 16,114,449, and caused 646,641 deaths (https://covid19.who.int/) [1]. The total numbers of COVID-19 cases diagnosed in the United States of America and Europe are 6,004,685, and 2,827,789, respectively [2]. Since it was first reported in Wuhan,
China at the end of 2019, infection of SARS-CoV-2 virus has become a global pandemic [3]. Here, we try to summarize current understanding of medicines, vaccines and nutrition impacts on the prevention and treatment of COVID-19, and try to provide nutritional considerations for those people impacted. We have used the following key words to retrieve information from published scientific research papers and reports, COVID-19, SARSCoV2, coronavirus, therapies, convalescent plasma, chloroquine, hydrochloroquine, remdesivir, vaccines, 
nutrition status, viral infectious diseases, smallpox, measles, vitamin A, B vitamins, Vitamin C, Vitamin D, lifestyles change, dietary behaviors, and physical activities.

\section{CORONAVIRUS AND HUMAN DISEASES}

The name of "coronavirus" derived from the "crownlike" outlook of the virus under the electron microscope [4]. Coronaviruses are a family of positive-single strand RNA viruses with a diameter of 80 to $120 \mathrm{~nm}$, and some members are pathogens of humans and animals [5]. As shown in Figure 1A, the nucleocapsid consists of nucleocapsid $(\mathrm{N})$ protein and RNA genome, which are enclosed in an envelope made of phospholipids and proteins. The envelope contains multiple proteins such as the spike glycoprotein (S), the transmembrane protein $(\mathrm{M})$, and the membrane-spanning protein (E). The glycosylated peplomers are made up of protein $\mathrm{S}$, which is responsible for the "crown" shape [6]. Hemagglutininesterase (HE) is another type of glycoprotein found on the surface of a virion particle and forms smaller spike than that of protein $S$ [7].

Coronaviruses contain a positive-strand RNA about $30 \mathrm{~kb}$ $[8,9]$. This RNA strand contains a 5'-untranslated region, an open reading frame (orf) $1 \mathrm{a} / \mathrm{b}$, genes encoding various viral proteins, and a 3 '-untranslated region [10]. For
SARS-CoV-2, the orf1a/b is responsible for the synthesis of pp1a, pp1ab, and other 15 non-structural proteins [11, 12, 13]. SARS-CoV-2 and SARS-CoV share dramatic homogeneity. SARS-CoV-2 only lacks 8a protein and has different $3 c$ and $8 b$ proteins compared with SARS-CoV [10].

Like other viruses, SARS-CoV-2 need host cells to replicate. Figure $1 \mathrm{~B}$ shows the entry and replication processes of SARS-CoV-2. The S protein interacts with its receptor on the cell membrane, which leads to the fusion of viral envelope and the host cell membrane. The release of SARS-CoV-2 content into the host cell starts the translation of viral proteins, synthesis of viral RNA strand, and assembly of new viruses. In the host cell, pp1a and pp1ab are first translated, and processed to form replicase complex. The nucleocapsid is the template to synthesize mRNA. The replicase complex supports to transcribe a collection of sub mRNAs and genome RNA. These mRNA molecules are templates to synthesis proteins of virions. The newly synthesized RNA containing the viral genome is assembled with other proteins to made new viruses, which are secreted from the host cell [10]. The secreted viruses enter the host tissue and circulation to initiate another round of infection and replication [10].

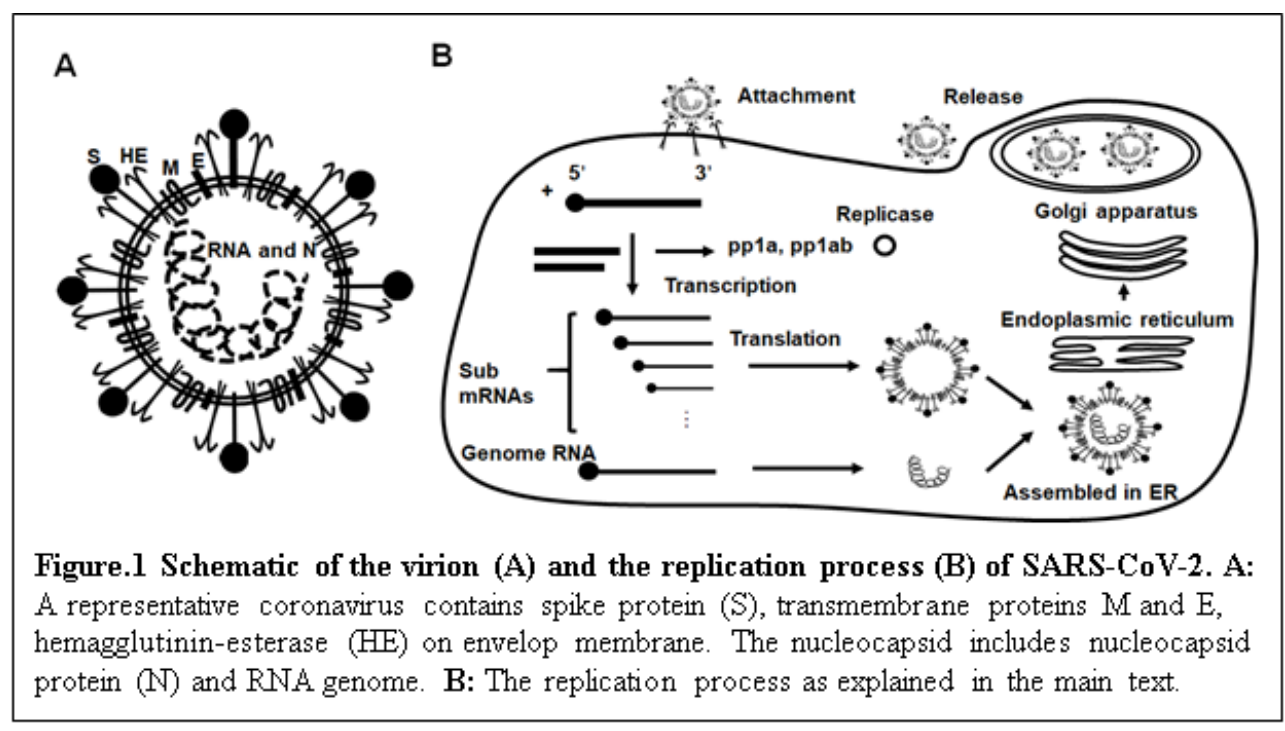

As shown in Figure 2, coronaviruses are hosted in wild animals and generally transmitted among them. The exposure of an individual to an infected wild animal initiates the animal to human transmission. After that, the infected human subject may transmit the virus to other human subjects through social activities, which leads to its epidemic in human populations [10]. The infection of coronaviruses in humans may cause both acute and chronic symptoms in respiratory, gastrointestinal, and central nervous systems [14]. As listed in Table 1, the three most recent reported coronavirus pandemics are severe acute respiratory syndrome (SARS, first reported in 2003), middle East respiratory syndrome (MERS, first reported in 2012) and acute respiratory syndrome coronavirus 2 (COVID-19, first reported in 2020) in the chronological order [15, 16, 17]. COVID-19 is attributed to the infection of SARS-CoV-2. Both SRAS-CoV and SARS-CoV-2 caused severe public panic. The basic reproductive values (R0) of SARS-CoV are about 2 to 5 $[18,19]$. The estimated R0 of SARS-CoV-2 is 2.68 [20]. SRAS-CoV had infected 8,098 human subjects in 26 countries and had a mortality of $9 \%$ in 2003. MERS infected 2,494 human subjects and caused 858 deaths (a mortality of 34.4\%) at the end of December, 2019 [21]. There were 2012 MERS cases reported in Saudi Arabia with a mortality of $37.1 \%$ [21]. WHO reported that SARS-CoV-2 has infected 16,114,449 human subjects and caused 646,641 deaths on July 27, 2020 [1]. 


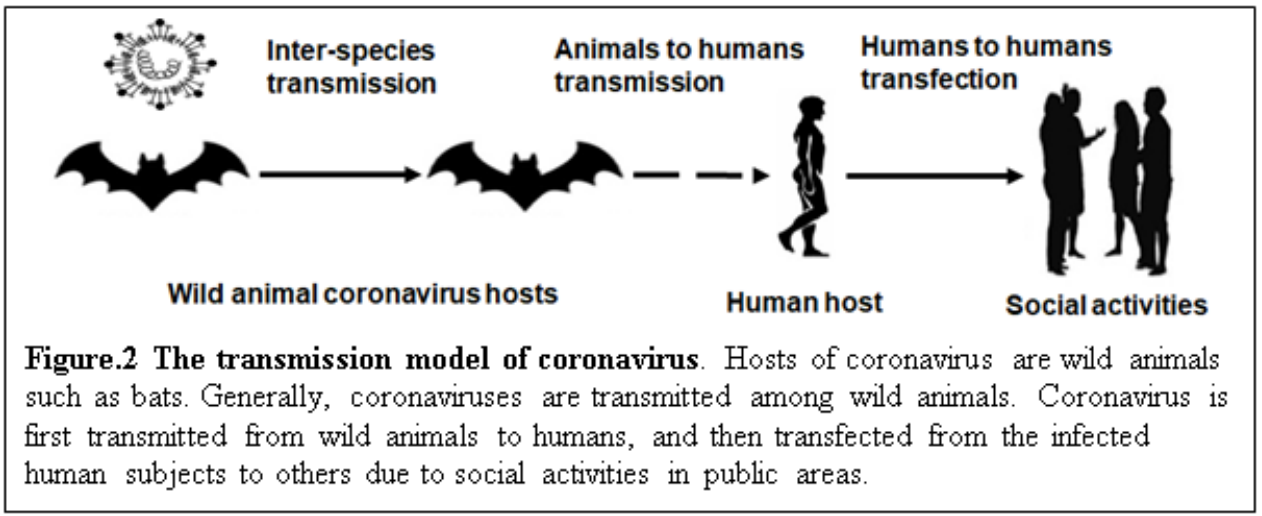

Table 1. Three most recent reported coronavirus pandemic-SARS, MERS, and COVID-19.

\begin{tabular}{lllll}
\hline Name & Virus & Time & $\begin{array}{l}\text { COVID-19 vaccine in the } \\
\text { process of development }\end{array}$ & $\begin{array}{l}\text { Specific } \\
\text { drug }\end{array}$ \\
\hline SARS & SARS-CoV & 2003- 2004 & No & No \\
MERS & MERS-CoV & $2012(2015)$ & No & No \\
COVID-19 & SARS-CoV-2 & Dec. 2019 to present & No & No \\
\hline
\end{tabular}

\section{CURRENT STATUS OF COVID-19 THERAPIES}

Potential or proven effective treatments of COVID-19 disease include but not limited to the application of convalescent plasma [22, 23, 24], chloroquine or hydroxychloroquine [26, 27, 28], and compassionate use of remdesivir [23, 29]. Moreover, researchers are actively developing vaccines and multiple clinical trials are in progress to collect efficacy and safety data.

Convalescent plasma. Convalescent plasma has been used to treat different types of disease, such as measles and SARS. Based on a recent study, SARS-CoV-2 and SARS-CoV have the similar binding affinities to angiotensin-converting enzyme 2 (ACE2) on host cells, the receptor for the $S$ protein [22]. The entry of SARS-CoV-2 into the host cells can be inhibited by polyclonal antibodies in the convalescent plasma. According to the recent data, plasma of convalescent patients of COVID-19 contains neutralizing antibodies [23]. In an uncontrolled study that includes 5 severe cases of COVID-19 supported with mechanical ventilation, the clinical symptoms of those cases improved after they received convalescent plasma 10-22 days after hospitalization [24]. This success leads the medical researchers to consider the potential and possibilities of collecting plasma of COVID-19 convalescent patients to prevent the deterioration of infected COVID-19 cases in the early stage [24].

Chloroquine. Chloroquine is a drug for the treatment of malaria [25]. In-vitro studies show that chloroquine can inhibit SARS-CoV and MERS-CoV proliferation [26]. Chloroquine at $6.90 \mu \mathrm{M}$ decreases the viral replication in Vero E6 cells [27]. The safety and efficacy of chloroquine have been tested in clinical trials. One 10day clinical study in Guangdong, China from January to February, 2020, included 22 COVID-19 moderate to severe cases that were randomized in two group: 10 patients receiving chloroquine $500 \mathrm{mg}$ orally twice daily, and 12 patients receiving lopinavir/ritonavir 400/100 mg orally twice daily [28]. At 7, 10 and 14 days, 70\%, 90\%, and $100 \%$ of patients in chloroquine group, and $58.33 \%$, $75 \%$, and $91.67 \%$ of lopinavir/ritonavir group become SARS-CoV-2 negative, respectively, showing that slightly higher percentage of patients in chloroquine group turns into negative than the control group [28]. Additionally, the incidence percentage of lung improvement of the chloroquine group is also improved in comparison to that of the lopinavir/ritonavir group [28].

Hydroxychloroquine. Hydroxychloroquine is a derivative of chloroquine and less toxic than chloroquine [29]. However, hydroxychloroquine is not effective for the treatment of COVID-19. A French clinical trial includes 11 severe COVID-19 cases who received hydroxychloroquine (600 mg/d for 10 days) and azithromycin (500 mg day 1 and 250 mg days 2 to 5), and does not show any evidence of a significant clinical and antiviral improvement [30]. Another study with 30 cases of moderate COVID-19 cases in Shanghai, China, does not show the efficacy of hydroxychloroquine compared with the control group [31]. The indicators evaluated include median duration from hospitalization to viral nucleic acid negative conversion in throat swabs, the median time for body temperature normalization, and CT images [31]. In an open label, randomized control trial that includes 150 mild to moderate COVID-19 patients, the percent of negative conversion in the hydroxychloroquine group is $85.4 \%$, which is similar to $81.3 \%$ of the standard of care group by 28 days [32]. In brief, studies of hydroxychloroquine appear to show no significant effects.

Remdesivir. Remdesivir produced by Gilead Science Inc is a nucleotide analogue prodrug which inhibits viral RNA polymerases. In vitro studies have shown that remdesivir can inhibit replications of coronavirus [27]. The EC90 value of remdesivir against SARS-CoV2 (2019-nCoV) in Vero E6 cells is $1.76 \mu \mathrm{M}$ [27]. It has 
been reported that the severe symptoms of one patient with COVID-19 in the United States were relieved well after treated with remdesivir [33]. Clinical studies had been in China to analyze safety and efficacy of remdesivir in adults with mild and moderate COVID-19 cases (NCT04252664), and severe COVID-19 cases (NCT04257656). However, clinical trials of NCT04252664 and NCT04257656 did not continue after April 15, 2020 as no eligible patients can be further recruited under the circumstance of well controlled COVID-19 epidemic (https://clinicaltrials.gov). A compassionate cohort study of remdesivir included severe COVID-19 hospitalized cases in the United States (22 cases), Europe and Canada (22 cases), and Japan (9 cases). Remdesivir treatment shows clinical improvement in 36 of 53 patients [34].

In one randomized, double-blind, placebo-controlled, multicenter trial study in Wuhan, China, remdesivir shows no significant effect on the treatment of COVID19. Remdesivir treatment does not improve the time to clinical improvement in 237 cases (158 cases in remdesivir and 79 cases in the control groups) [35]. Additionally, mortality rates on Day 28 are similar in the two groups, 22/158 death in the remdesivir group and $10 / 79$ death in the placebo group. Different results seem to be seen when remdesivir is used to treat COVID-19 patients. Whether the genetic background of the patients, the severity of the disease and the time of intervention play a role in this difference remains to be revealed. Further efficacy data are expected from randomized, placebo-controlled clinical studies of remdesivir treatments.

\section{VACCINES}

Researchers have identified a group of $\mathrm{B}$ and $\mathrm{T}$ cell epitopes derived from the $\mathrm{S}$ and $\mathrm{N}$ proteins of SARSCoV-2 [37]. On June 24, 2020, WHO reported the draft landscape of COVID-19 candidate vaccines. According to the report, there are 16 candidate vaccines under clinical evaluation and 125 candidate vaccines under preclinical evaluation [38]. The 16 candidate vaccines in clinical trials are listed in Table 2. Currently, different methods have been used to develop vaccines against coronaviruses.

Whole-inactivated virus is one vaccine type, which uses the whole pathogen cultured and treated in lab [36]. There are four clinical trials in progress to develop the whole-inactivated coronavirus vaccines. The first one by Wuhan Institute of Biological Products and Sinopharm started on April 11, 2020. The most recent one is developed by Institute of Medical Biology, Chinese Academy of Medical Sciences, which was started on May 15, 2020.

Another type of vaccine is coronavirus mRNA, which is generally encapsulated in lipids for delivery. The first phase I clinical trial of a novel lipid nanoparticleencapsulated mRNA-based vaccine began in the United States on March 16, 2020. The mRNA sequence encodes the $\mathrm{S}$ protein of SARS-CoV2 [39]. The most recent one started on June 18, 2020 and is developed by Curevac in Germany.

Table 2. Current COVID-19 candidate vaccines as of June 24, 2020.

\begin{tabular}{lll}
\hline Start date & Type of vaccine & Developer \\
\hline $\mathbf{0 4 - 1 1 - 2 0 2 0}$ & Inactivated & Wuhan Institute of Biological Products/Sinopharm \\
$\mathbf{0 4 - 1 6 - 2 0 2 0}$ & Inactivated & Sinovac \\
$\mathbf{0 4 - 2 8 - 2 0 2 0}$ & Inactivated & Beijing Institute of Biological Products/Sinopharm \\
$\mathbf{0 5 - 1 5 - 2 0 2 0}$ & Inactivated & Institute of Medical Biology, Chinese Academy of Medical Sciences \\
$\mathbf{0 3 - 1 6 - 2 0 2 0}$ & mRNA & Moderna/NIAID \\
$\mathbf{0 4 - 0 1 - 2 0 2 0}$ & mRNA & Imperial College London \\
$\mathbf{0 4 - 2 0 - 2 0 2 0}$ & mRNA & BioNTech/Fosun Pharma/Pfizer \\
$\mathbf{0 6 - 1 8 - 2 0 2 0}$ & mRNA & Curevac \\
$\mathbf{0 3 - 1 6 - 2 0 2 0}$ & Viral Vector & CanSino Biological Inc./Beijing Institute of Biotechnology \\
$\mathbf{0 3 - 1 9 - 2 0 2 0}$ & Viral Vector & University of Oxford/AstraZeneca \\
$\mathbf{0 6 - 1 7 - 2 0 2 0}$ & Viral Vector & Gamaleya Research Institute \\
$\mathbf{0 5 - 2 5 - 2 0 2 0}$ & Protein Subunit & Novavax \\
$\mathbf{0 6 - 1 9 - 2 0 2 0}$ & Protein Subunit & Clover Biopharmaceuticals Inc./GSK/Dynavax \\
$\mathbf{0 6 - 2 2 - 2 0 2 0}$ & Protein Subunit & Anhui Zhifei Longcom Biopharmaceutical/Institute of Microbiology, \\
$\mathbf{0 4 - 0 3 - 2 0 2 0}$ & DNA & Chinese Academy of Sciences \\
\hline $\mathbf{0 6}$ & DNA & Genexine Consortium \\
\hline
\end{tabular}


Non-replicating viral vector is a traditional method for vaccine development. Genes encoding the proteins of coronavirus can be inserted into a carrier virus for delivery in humans [40]. The first one of this kind of vaccines is developed by CanSino Biological Inc. and Beijing Institute of Biotechnology, and started on March 16, 2020. The most recent one is developed by Gamaleya Research Institute and started on June 17, 2020.

Protein subunit is the type of protein vaccines consisting of antigens that have either been produced in bacteria and yeast or purified from the coronavirus [42]. The first one is developed by Novavax, and started on May 25, 2020. The most recent one is developed by Anhui Zhifei Longcom Biopharmaceutical and Institute of Microbiology, Chinese Academy of Science, and started on June 22, 2020.

DNA vaccine is a novel type of vaccine expressing the $\mathrm{S}$ protein [41]. The first one started on April 3, 2020 which is developed by Inovio Pharmaceuticals. In one DNA coronavirus vaccine, the SARS-CoV-2 S glycoprotein sequence was generated after performing a sequence alignment. Then the N-terminal IgE leader sequence was added for expression in a vector [41]. The most recent clinical trial of DNA coronavirus vaccine started on June 17, 2020 and is developed by Genexine Consortium.

\section{NUTRITIONAL CONSIDERATIONS AND COVID- 19 PANDEMIC}

Nutrition status is associated with immunity closely, which is essential for the body to combat infectious diseases caused by viruses. Adequate nutrition status helps to prevent infection, improves the rate of vaccination and reduces the mortality rate of infected subjects. For example, measles, a viral infectious disease, still presents in certain areas of the world [43]. Vitamin A supplementation has been shown to attenuate the infection of measles in children up to 6 months [44]. In Guinea-Bissau, a placebo-controlled trial in newborns babies with normal body weight has been done. In the first 6 months age of babies, vitamin A supplementation (50,000 IU) can influence the incidence and susceptibility of measles in the boys, but not the girls [44]. Data from WHO have shown that children received measles vaccine together with vitamin A supplementation at age of 9 months demonstrate better efficacy than those controls. The specific antibody concentrations of measles in children of the vitamin A supplementation group at age of 18 months are higher than the measles vaccine only placebo group [45]. The benefits of vitamin A supplementation are not limited to measles prevention and vaccination. For those infected cases of measles, mortality and morbidity decreased in the supplementation group [46].

Given the importance of nutrition in maintaining the health status, it is reasonable to explore the potential roles of nutrients to prevent and treat COVID-19 alone or in combination with available medicines. Here, we try to summarize potential nutrition interventions for COVID19.

Vitamin A (retinol). Vitamin A is a lipophilic micronutrient that contributes to a variety of physiological processes including immunity [47]. We have searched the PUBMED for the effects of vitamin A on the infection of coronavirus. The function of bovine coronavirus vaccines decreases in bovine fed low vitamin A diets [48]. Another study shows that chicken fed a vitamin A sufficient diet have less infection of bronchitis virus than those fed a deficient diet [49]. Currently, there is no pre-clinical studies to test the effect of retinoids on COVID-19 as of July 14, 2020 [50]. One clinical study was registered in Iran (https://www.irct.ir/trial/46838) to study the intervention of vitamin A $(25,000$ IU daily for 7 days) on improvement and mortality rates in ICU patients with COVID-19. We are expecting more studies to explore the effects of vitamin A on COVID-19 in vitro or in vivo.

$B$ vitamins. B vitamins are water-soluble. It has been shown that vitamin B2 in combination with ultraviolent light reduces the titers of MERS coronavirus in human plasma inoculated with MERS coronavirus in vitro [51]. Vitamin B3 significantly inhibits neutrophil infiltration into the lung of mice with ventilator-induced lung injury [52]. One clinical trial (ClinicalTrials.gov Identifier: NCT04407572) was conducted in Turkey between April 20, 2020 to June 1,2020 , which is aimed to evaluate the effects of serum zinc, vitamin D, and vitamin B12 levels on 45 COVID-19 positive pregnant women. It also planned to study on the association between vitamin D level and vitamin B12 level in those subjects. The data are yet to be shown.

Vitamin C. As a water-soluble vitamin, vitamin C dietary reference index is 75 to $90 \mathrm{mg}$ per day and the upper intake is less than $2 \mathrm{~g}$ per day based on the suggestion from National Institute of Health [55]. Excessive vitamin $\mathrm{C}$ in the tubules of kidney can be excreted into the urine [56]. The safety of high dose of intravenous injection of vitamin $\mathrm{C}$ is not a concern because of the secretion process. Infection of coronavirus leads to death and lung injuries due to respiratory distress syndrome (ARDS), which is associated with oxidative stress caused by increases of free radicals and cytokines [53]. Vitamin C acts as an antioxidant to receive electrons from free radicals, and in turn, reduced oxidative stress [53]. In a randomized control study performed in the United States, the mortality of 167 sepsis ARDS cases decreases with the clinical administration of near 15 grams of vitamin C per day for four days [54]. Another study shows that the oxidative stress caused by acute inflammatory lung injury in cases receiving mechanical ventilation decreases with dietary vitamin C supplementation [55].

In Wuhan China, a clinical trial has been approved to investigate the influence of vitamin $\mathrm{C}$ in severe COVID19 cases. One hundred forty patients are randomly divided into two groups, intravenous vitamin $\mathrm{C}$ group (a dose of 24 g/day for 7days) or placebo group. Data are collected based on assessment of organ failure scores, length of stay in ICU, etc [57]. There are a total 16 officially registered clinical trials related with vitamin C as shown in Table 3. Subjects have not been recruited in five clinical trials (ClinicalTrials.gov Identifiers: NCT04347889, NCT04395768, NCT04363216, NCT04401150, NCT04344184). One clinical trial related 
with vitamin C (ClinicalTrials.gov Identifier: NCT04334967) was suspended. Ten clinical trials are recruiting subjects (ClinicalTrials.gov Identifiers: NCT04264533, NCT04323514, NCT04328961, NCT04357782, NCT04354428, NCT04370288, NCT04468139, NCT04335084, NCT04334512,
NCT03680274). Vitamin C is applied either by dietary supplementation or by high dose of intravenous injection in those clinical studies. We are looking forward for the final clinical data, thus to help us further understand the role of vitamin C in COVID-19.

Table 3. Registered clinical studies of the relationship between Vitamin C and COVID-19 infection in ClinicalTrials.gov.

\begin{tabular}{|c|c|c|c|}
\hline Start date & Status & Identifier & Study Title \\
\hline 11-8-2018 & Recruiting & NCT03680274 & Lessening Organ Dysfunction With VITamin C \\
\hline 02-14-2020 & Recruiting & NCT04264533 & $\begin{array}{l}\text { Vitamin C Infusion for the Treatment of Severe 2019-nCoV Infected } \\
\text { Pneumonia }\end{array}$ \\
\hline 03-13-2020 & Recruiting & NCT04323514 & Use of Ascorbic Acid in Patients With COVID 19 \\
\hline 03-30-2020 & Suspended & NCT04334967 & $\begin{array}{l}\text { Hydroxychloroquine in Patients With Newly Diagnosed COVID-19 } \\
\text { Compared to Standard of Care }\end{array}$ \\
\hline 03-31-2020 & Recruiting & NCT04328961 & Hydroxychloroquine for COVID-19 Post-exposure Prophylaxis \\
\hline 04-16-2020 & Recruiting & NCT04357782 & $\begin{array}{l}\text { Administration of Intravenous Vitamin C in Novel Coronavirus Infection } \\
\text { (COVID-19) and Decreased Oxygenation }\end{array}$ \\
\hline 04-16-2020 & Recruiting & NCT04354428 & Treatment for COVID-19 in High-Risk Adult Outpatients \\
\hline 04-19-2020 & Recruiting & NCT04370288 & $\begin{array}{l}\text { Clinical Application of MCN (Methylene blue, vitamin C, N-acetyl } \\
\text { cysteine) for Treatment of Covid-19 Patients }\end{array}$ \\
\hline 04-20-2020 & Not recruiting & NCT04347889 & Preventing COVID-19 in Healthcare Workers With HCQ: A RCT \\
\hline 05-2020 & Not recruiting & NCT04363216 & $\begin{array}{l}\text { Pharmacologic Ascorbic Acid as an Activator of Lymphocyte Signaling for } \\
\text { COVID-19 Treatment }\end{array}$ \\
\hline 05-25-2020 & Not recruiting & NCT04395768 & $\begin{array}{l}\text { International ALLIANCE Study of Therapies to Prevent Progression of } \\
\text { COVID-19 }\end{array}$ \\
\hline 06-2020 & Not recruiting & NCT04401150 & Lessening Organ Dysfunction With VITamin C - COVID-19 \\
\hline 06-20-2020 & Recruiting & NCT04468139 & $\begin{array}{l}\text { The Study of Quadruple Therapy Zinc, Quercetin, Bromelain and Vitamin C } \\
\text { on the Clinical Outcomes of Patients Infected With COVID-19 }\end{array}$ \\
\hline $06-22-2020$ & Recruiting & NCT04335084 & $\begin{array}{l}\text { A Study of Hydroxychloroquine, Vitamin C, Vitamin D, and Zinc for the } \\
\text { Prevention of COVID-19 Infection }\end{array}$ \\
\hline $06-22-2020$ & Recruiting & NCT04334512 & A Study of Quintuple Therapy to Treat COVID-19 Infection \\
\hline $10-2020$ & Not recruiting & NCT04344184 & $\begin{array}{l}\text { Early Infusion of Vitamin C for Treatment of Novel COVID-19 Acute Lung } \\
\text { Injury }\end{array}$ \\
\hline
\end{tabular}

Vitamin D. Vitamin D is made endogenously when its precursor is converted to the active form under the condition of ultraviolet radiation on the skin. It is derived from either food source or supplements [58]. It plays protective roles on experimental interstitial pneumonitis in lung tissues [61]. Additionally, vitamin D exerts important role in keeping the homeostasis of respiratory via inhibiting virus replication and stimulating the secretion of antimicrobial peptides [62]. Vitamin D supplementation is found to decrease the infection of respiratory tract significantly in a placebo-controlled study with 5,660 cases [68]. According to a recent review, vitamin D may help to decrease the incidence and mortality of COVID-19 [59]. The functional mechanisms of vitamin D include decrease of the cytokine storm, inhibition of $\mathrm{T}$ helper cell type 1 responses and stimulation of $\mathrm{T}$ cells [51]. Lymphopenia is one of the manifestations of COVID-19 [60]. In severe COVID-19 cases, vitamin D insufficiency is associated with ARDS [63]. Clinical studies show that blood 25(OH)D level is negatively associated with the productions of cytokines, ARDS, and other symptoms in COVID-19 patients [64, $65,66]$. Moreover, vitamin D supplementation is shown to decrease the risk of respiratory diseases in one randomized trial [67].

A total of six clinical trials are under recruiting status (ClinicalTrials.gov Identifiers: NCT04386850, NCT04344041, NCT04403932, NCT04407286, NCT04459247, NCT04335084, NCT04449718) as shown in Table 4. Two clinical studies have been completed (ClinicalTrials.gov Identifiers: NCT04435119, NCT04407572). One of the two are set to investigate levels of zinc, vitamin D and B12 in the COVID-19 positive pregnant women (details are not released yet). 
Another one (ClinicalTrials.gov Identifier: NCT04435119) evaluates the potential role of vitamin D3 supplementation in survival rate of COVID-19 in sensitive elder people. It appears that vitamin D has been considered as a potential way to help the combat against COVID-19.

Table 4. Registered clinical studies of the relationship between Vitamin D and COVID-19 in ClinicalTrials.gov.

\begin{tabular}{|c|c|c|c|}
\hline Start date & $\begin{array}{l}\text { Recruiting } \\
\text { Status }\end{array}$ & Identifier & Study Title \\
\hline 04-14-2020 & Recruiting & NCT04386850 & Oral 25-hydroxyvitamin D3 and COVID-19 \\
\hline 04-15-2020 & Recruiting & NCT04344041 & $\begin{array}{l}\text { COvid-19 and Vitamin D Supplementation: a Multicenter Randomized } \\
\text { Controlled Trial of High Dose Versus Standard Dose Vitamin D3 in High- } \\
\text { risk COVID-19 Patients (CoVitTrial) }\end{array}$ \\
\hline 04-17-2020 & Recruiting & NCT04403932 & $\begin{array}{l}\text { Increased Risk of Severe Coronavirus Disease } 2019 \text { in Patients With } \\
\text { Vitamin D Deficiency }\end{array}$ \\
\hline 05-19-2020 & Recruiting & NCT04407286 & Vitamin D Testing and Treatment for COVID 19 \\
\hline 06-15-2020 & Recruiting & NCT04459247 & Short Term, High Dose Vitamin D Supplementation for COVID-19 \\
\hline 06-22-2020 & Recruiting & NCT04335084 & $\begin{array}{l}\text { A Study of Hydroxychloroquine, Vitamin C, Vitamin D, and Zinc for the } \\
\text { Prevention of COVID-19 Infection }\end{array}$ \\
\hline $11-30-2020$ & Recruiting & NCT04449718 & Vitamin D Supplementation in Patients With COVID-19 \\
\hline 03-15-2020 & Completed & NCT04435119 & Covid-19 and Vitamin D in Nursing-home \\
\hline 04-20-2020 & Completed & NCT04407572 & $\begin{array}{l}\text { Evaluation of the Relationship Between Zinc Vitamin D and b12 Levels in } \\
\text { the Covid-19 Positive Pregnant Women }\end{array}$ \\
\hline
\end{tabular}

As summarized here, both clinical and epidemiological studies have been conducted to investigate the role of vitamins in the treatment and prevention of COVID-19. Both types of studies have many potential influencing factors, for example, it is difficult to expel the effects of food containing vitamins in human body. In addition, it is impossible to only take vitamin supplements to demonstrate their efficacy in human body. Moreover, intervention studies need to include sufficient subjects to ensure that the data are statistically significant.

\section{THE BEHAVIORAL AND LIFESTYLE CHANGES OF HUMANS IN THE COVID-19 PANDEMIC}

COVID-19 pandemic has unprecedentedly altered people's lifestyles and dietary behaviors. The state-athome order or self-quarantine may limit routine physical activities. Staying at home for a relative long time may cause emotional depression. A large-scale general population study has examined lifestyle risk factors in cohort data with national hospitalization registration in the United Kingdom [69]. The study includes 387,109 participants living in England from UK Biobank study. The results show that unhealthy lifestyle similar to noncommunicable disease which is also a risk factor for COVID-19. Keeping a simple lifestyle could decrease the possibility of severe infection [69].

Maintenance of healthy lifestyle can be especially difficult for adolescents. Data of dietary intake collected from 820 adolescents between 10-19 years old residing in Spain, Italy, Brazil, Colombia, and Chile show that confinement during COVID-19 pandemic indeed influences their dietary behaviors [70]. In a clustering analysis study, the household dietary diversity score
(HDDS) is evaluated among 1,938 subjects in China. Food sources are mainly from in-house storage and personal grocery purchase during the quarantine time. About $55.9 \%$ of participants purchased food online for at least one time. Near $37.7 \%$ of participants take nutrition supplements such as vitamin C, probiotics, other dietary supplements to prevent COVID-19. The HDDS of those taking specific supplements is significantly higher than that of those not-intaking [71].

Physical activity is also affected by the COVID-19 home confinement. An online survey collected information from 1,047 participants (46\% men) in Asia (36\%), Africa (40\%), and Europe (21\%). The confinement has negatively impacted all physical activity intensity levels (vigorous, moderate, walking and overall). Daily sitting time increases from 5 to 8 hours per day [72]. A qualitative interview survey including 8 professionals (managers working in physical activity programs for ordinary elders or sports trainers) and 6 ordinary elders in France shows that older adults are willing to conduct physical activity at home. Among older adults, physical inactivity is the fourth risk factor for mortality worldwide [73, 74]. It is important to help elders to perform simple and safe physical activities at home [74].

\section{CONCLUSIONS AND FUTURE PERSPECTIVES}

Here, we summarized the current understanding of genome structure and replication of SARS-CoV-2. Currently, potential medical treatments such as convalescent plasma, chloroquine, hydroxychloroquine, and compassionate use of remdesivir have been tested globally. The vaccines for COVID-19 are still in the phases of development. Moreover, potential contributions 
of vitamin A, B vitamins, vitamin C, and vitamin D are also in the process of being evaluated to find their roles in prevention and treatment of COVID-19. We believe that nutrition status and nutritional supplements should be considered when the lifestyle and dietary behaviors are altered profoundly by the COVID-19 pandemic. The nutritional considerations should not be limited to those infected by the SARS-CoV-2 virus. Healthy diets and sufficient physical activities should always be considered

\section{REFERENCES}

[1] World Health Organization. Coronavirus Disease (COVID-19) Dashboard. WHO. https://covid19.who.int/. (Data last updated: 2020/7/27, 6:58pm CEST)

[2] World Health Organization. Coronavirus disease (COVID-19) Situation Report - 170. WHO. https://www.who.int/docs/default-source/coronaviruse/situationreports/20200708-covid-19-sitrep-170.pdf?sfvrsn=bca86036_2 2 . (Data as received by WHO from national authorities by 10:00 CEST, 8 July 2020)

[3] Chen ZL, Zhang Q, Lu Y, et al. Distribution of the COVID-19 epidemic and correlation with population emigration from Wuhan, China. Chin Med J (Engl). 2020;133(9):1044-1050. doi:10.1097/CM9.0000000000000782

[4] Tyrrel, D. A. J., J. D. Almedia, D. M. Berry, C. H. Cunningham, D. Hamre, M. S. Hofstad, L. Malluci, and K. McIntosh. 1968. Coronavirus. Nature 220:650.

[5] Weiss SR, Navas-Martin S. Coronavirus pathogenesis and the emerging pathogen severe acute respiratory syndrome coronavirus. Microbiol Mol Biol Rev. 2005;69(4):635-664. doi:10.1128/MMBR.69.4.635-664.2005

[6] Bond, C. W., J. L. Leibowitz, and J. A. Robb. 1979. Pathogenic murine coronaviruses. II. Characterization of virus-specific proteins of murine coronaviruses JHMV and A59V. Virology 94:371-384.

[7] Brian, D. A., B. G. Hogue, and T. E. Kienzle. 1995. The coronavirus hemagglutinin esterase glycoprotein, p. 165179. In S. G. Siddell (ed.), The Coronaviridae. Plenum Press, New York, N.Y.

[8] Lee, H. J., C. K. Shieh, A. E. Gorbalenya, E. V. Koonin, N. La Monica, J. Tuler, A. Bagdzhadzhyan, and M. M. Lai. 1991. The complete sequence (22 kilobases) of murine coronavirus gene 1 encoding the putative proteases and RNA polymerase. Virology 180:567-582.

[9] Biological properties of avian coronavirus RNA. Lomniczi B J Gen Virol. 1977 Sep; 36(3):531-3.

[10] Muhammad Afnan Shereen, et al, Journal of Advanced Research. Volume 24, July 2020, Pages 91-98

[11] A. Wu, Y. Peng, B. Huang, X. Ding, X. Wang, P. Niu, et al. Genome composition and divergence of the novel coronavirus (2019-nCoV) originating in China Cell Host Microbe (2020)

[12] R. Lu, X. Zhao, J. Li, P. Niu, B. Yang, H. Wu, et al. Genomic characterisation and epidemiology of 2019 novel coronavirus: implications for virus origins and receptor binding Lancet, 395 (10224) (2020), pp. 565-574

[13] Y. Chen, Q. Liu, D. Guo Emerging coronaviruses: genome structure, replication, and pathogenesis $\mathrm{J}$ Med Virol (2020)

[14] McIntosh, K. 1974. Coronaviruses: a comparative review. Curr. Top. Microbiol. Immunol. 63:85-129.

[15] J. Peiris, Y. Guan, K. Yuen Severe acute respiratory syndrome Nat Med, 10 (12) (2004), pp. S88-S97 in the fight against this unprecedent global health challenge.

\section{AUTHORS' CONTRIBUTIONS}

Zhang Y and Chen G designed the outline and wrote the draft.

\section{CONFLICT-OF-INTEREST STATEMENT}

All authors declared no conflict of interest.

[16] A. Rahman, A. Sarkar Risk factors for fatal middle east respiratory syndrome coronavirus infections in Saudi Arabia: analysis of the WHO Line List, 2013-2018 Am J Public Health, 109 (9) (2019), pp. 1288-1293

[17] C. Wang, P.W. Horby, F.G. Hayden, G.F. Gao A novel coronavirus outbreak of global health concern The Lancet (2020)

[18] Chen J. Pathogenicity and transmissibility of 2019-nCoV—a quick overview and comparison with other emerging viruses. Microbes Infect. 2020;22(2), 10.1016/j.micinf.2020.01.004

[19] Zhao S, Lin Q, Ran J, et al. Preliminary estimation of the basic reproduction number of novel coronavirus (2019-nCoV) in China, from 2019 to 2020: a data-driven analysis in the early phase of the outbreak. Int J Infect Dis. 2020;92:214-217.

[20] Wu JT, Leung K, Leung GM. Nowcasting and forecasting the potential domestic and international spread of the 2019-nCoV outbreak originating in Wuhan, China: a modelling study. Lancet. 2020;395:689-697.

[21] World Health Organization. Middle East respiratory syndrome coronavirus (MERS-CoV). WHO. https://www.who.int/emergencies/mers-cov/en/. (Data as received by WHO from national authorities by November 2029)

[22] Walls AC, Park YJ, Tortorici MA, et al .: Structure, function, and antigenicity of the SARS-CoV-2 spike glycoprotein. Cell 2020. pii: S0092-8674(20)30262-2

[23] Woelfel R, Comran VM, Guggemos W, et al .: Clinical presentation and virological assessment of hospitalized cases of coronavirus disease 2019 in a travel-associated transmission cluster. medRxiv 2020. 03.05.20030502 (not peer-reviewed yet)

[24] Shen C, Wang Z, Zhao F, et al.: Treatment of 5 Critically Ill Patients With COVID-19 With Convalescent Plasma. JAMA 2020. doi:10.1001/jama.2020.4783

[25] White NJ. The treatment of malaria. N Engl J Med. 1996;335(11):800-806. doi:10.1056 /N EJM 1996091 23351107

[26] Savarino A., Boelaert J.R., Cassone A., Majori G., Cauda R. Effects of chloroquine on viral infections: an old drug against today's diseases? Lancet Infect Dis. 2003;3:722727.

[27] Wang M., Cao R., Zhang L., Yang X., Liu J., Xu M. Remdesivir and chloroquine effectively inhibit the recently emerged novel coronavirus (2019-nCoV) in vitro. Cell Res. 2020 doi: 10.1038/s41422-020-0282-0.

[28] Huang M, Tang T, Pang P, et al. Treating COVID-19 with Chloroquine. J Mol Cell Biol. 2020;12(4):322-325. doi:10.1093/jmcb/mjaa014

[29] McChesney EW. Animal toxicity and pharmacokinetics of hydroxychloroquine sulfate. Am J Med. 1983;75(1A):1118. doi:10.1016/0002-9343(83)91265-2 
[30] Molina JM, Delaugerre C, Le Goff J, et al. No evidence of rapid antiviral clearance or clinical benefit with the combination of hydroxychloroquine and azithromycin in patients with severe COVID-19 infection. Med Mal Infect. 2020;50(4):384. doi:10.1016/j.medmal.2020.03.006

[31] A pilot study of hydroxychloroquine in treatment of patients with moderate COVID-19. J Zhejiang Univ (Med Sci) 2020, Vol. 49 Issue (2): 215-219. doi: 10.3785/j.issn.1008-9292.2020.03.03

[32] Tang W, Cao Z, Han M, et al. Hydroxychloroquine in patients with mainly mild to moderate coronavirus disease 2019: open label, randomised controlled trial. BMJ. 2020;369:m1849. Published 2020 May 14. doi:10.1136/bmj.m1849

[33] Michelle L Holshue, Chas DeBolt, Scott Lindquist. First Case of 2019 Novel Coronavirus in the United States. 2020 The New England Journal of Medicine Volume: 382, Issue: 10 , pp 929-936 doi: 10.1056/NEJMOA2001191

[34] Grein J, Ohmagari N, Shin D, et al. Compassionate Use of Remdesivir for Patients with Severe Covid-19. N Engl J Med. 2020;382(24):2327-2336. doi:10.1056/NEJMoa2007016

[35] Wang Y, Zhang D, Du G, et al. Remdesivir in adults with severe COVID-19: a randomised, double-blind, placebocontrolled, multicentre trial [published correction appears in Lancet. 2020 May 30;395(10238):1694]. Lancet. 2020;395(10236):1569-1578. doi:10.1016/S0140-6736(20)31022-9

[36] Graham BS. Rapid COVID-19 vaccine development. Science. 2020;368(6494):945-946. doi:10.1126/science.abb8923

[37] Ahmed SF, Quadeer AA, McKay MR. Preliminary Identification of Potential Vaccine Targets for the COVID-19 Coronavirus (SARS-CoV-2) Based on SARSCoV Immunological Studies. Viruses. 2020;12(3):254. Published 2020 Feb 25. doi:10.3390/v12030254

[38] World Health Organization. DRAFT landscape of COVID-19 candidate vaccines. WHO.

https://www.who.int/publications/m/item/draft-landscapeof-covid-19-candidate-vaccines. (Data last updated: 24 June 2020)

[39] Wang F, Kream RM, Stefano GB. An Evidence Based Perspective on mRNA-SARS-CoV-2 Vaccine Development. Med Sci Monit. 2020;26:e924700. Published 2020 May 5. doi:10.12659/MSM.924700

[40] Robert-Guroff M. Replicating and non-replicating viral vectors for vaccine development. Curr Opin Biotechnol. 2007;18(6):546-556. doi:10.1016/j.copbio.2007.10.010

[41] Smith TRF, Patel A, Ramos S, et al. Immunogenicity of a DNA vaccine candidate for COVID-19. Nat Commun. 2020;11(1):2601. Published 2020 May 20. doi:10.1038/s41467-020-16505-0

[42] Effects of malnutrition on smallpox and yellow fever vaccination. Nutr Rev. 1967;25(4):108-110. doi:10.1111/j.1753-4887.1967.tb05593.x

[43] Bester JC. Measles and Measles Vaccination: A Review. JAMA Pediatr. 2016;170(12):1209-1215. doi:10.1001/jamapediatrics.2016.1787

[44] Diness BR, Martins CL, Balé C, et al. The effect of highdose vitamin A supplementation at birth on measles incidence during the first 12 months of life in boys and girls: an unplanned study within a randomised trial. Br J Nutr. 2011;105(12):1819-1822.
doi:10.1017/S0007114510005532

[45] Benn CS, Balde A, George E, et al. Effect of vitamin A supplementation on measles-specific antibody levels in Guinea-Bissau. Lancet. 2002;359(9314):1313-1314. doi:10.1016/S0140-6736(02)08274-0

[46] Barclay AJ, Foster A, Sommer A. Vitamin A supplements and mortality related to measles: a randomised clinical trial. Br Med J (Clin Res Ed). 1987;294(6567):294-296. doi:10.1136/bmj.294.6567.294

[47] Zhang L, Liu Y. Potential interventions for novel coronavirus in China: A systematic review. J Med Virol. 2020;92(5):479-490. doi:10.1002/jmv.25707

[48] Jee J, Hoet AE, Azevedo MP, et al. Effects of dietary vitamin A content on antibody responses of feedlot calves inoculated intramuscularly with an inactivated bovine coronavirus vaccine. Am J Vet Res. 2013;74:1353-1362. 10.2460/ajvr.74.10.1353

[49] West CE, Sijtsma SR, Kouwenhoven B, Rombout JH, van der Zijpp AJ. Epithelia-damaging virus infections affect vitamin A status in chickens. J Nutr. 1992;122:333-339. 10.1093/jn/122.2.333

[50] Trasino SE. A role for retinoids in the treatment of COVID-19? [published online ahead of print, 2020 May 27]. Clin Exp Pharmacol Physiol. 2020;10.1111/14401681.13354. doi:10.1111/1440-1681.13354

[51] Keil SD, Bowen R, Marschner S. Inactivation of Middle East respiratory syndrome coronavirus (MERS-CoV) in plasma products using a riboflavin-based and ultraviolet light-based photochemical treatment. Transfusion. 2016;56:2948-2952. 10.1111/trf.13860

[52] Kyme P, Thoennissen NH, Tseng CW, et al. $\mathrm{C} / \mathrm{EBP}$ epsilon mediates nicotinamide-enhanced clearance of Staphylococcus aureus in mice. $\mathrm{J}$ Clin Invest. 2012;122:3316-3329. 10.1172/JCI62070

[53] Cheng RZ. Can early and high intravenous dose of vitamin C prevent and treat coronavirus disease 2019 (COVID-19)?. Med Drug Discov. 2020;5:100028. doi:10.1016/j.medidd.2020.100028

[54] Fowler AA 3rd, Truwit JD, Hite RD, et al. Effect of Vitamin C Infusion on Organ Failure and Biomarkers of Inflammation and Vascular Injury in Patients With Sepsis and Severe Acute Respiratory Failure: The CITRIS-ALI Randomized Clinical Trial [published correction appears in JAMA. 2020 Jan 28;323(4):379]. JAMA. 2019;322(13):1261-1270. doi:10.1001/jama.2019.11825

[55] Patel V., Dial K., Wu J., Gauthier A.G., Wu W., Lin M. Dietary antioxidants significantly attenuate hyperoxiainduced acute inflammatory lung injury by enhancing macrophage function via reducing the accumulation of airway HMGB1. Int J Mol Sci. 2020;21:977.

[56] Krinsky N.I., Beecher G., Burk R., Chan A., Erdman j.J., Jacob R., Jialal I., Kolonel L., Marshall J., Taylor Mayne P.R. Dietary Reference Intakes for Vitamin C, Vitamin E, Selenium, and Carotenoids. The National Academies Press; Washington, DC, USA: 2000. A Report of the Panel on Dietary Antioxidants and Related Compounds, Subcommittees on Upper Reference Levels of Nutrients and Interpretation and Uses of Dietary Reference Intakes, and the Standing Committee on the Scientific Evaluation of Dietary Reference Intakes, Institute of Medicine.

[57] Ralli EP, Friedman GJ, Rubin SH. The mechanism of the excretion of vitamin c by the human kidney. J Clin Invest. 1938;17(6):765-770. doi:10.1172/JCI101006 
[58] Ali N. Role of vitamin D in preventing of COVID-19 infection, progression and severity [published online ahead of print, 2020 Jun 20]. J Infect Public Health. 2020;S1876-0341(20)30531-1. doi:10.1016/j.jiph.2020.06.021

[59] Grant W.B., Lahore H., McDonnell S.L., Baggerly C.A., French C.B., Aliano J.L. Evidence that vitamin D supplementation could reduce risk of influenza and COVID-19 infections and deaths. Nutrients. 2020;12:988.

[60] Tian Y., Rong L. Covid-19 and vitamin D-authors' reply. Aliment Pharmacol Ther. 2020

[61] Tsujino I., Ushikoshi-Nakayama R., Yamazaki T., Matsumoto N., Saito I. Pulmonary activation of vitamin D3 and preventive effect against interstitial pneumonia. J Clin Biochem Nutr. 2019;65:245-251.

[62] Zdrenghea M.T., Makrinioti H., Bagacean C., Bush A., Johnston S.L., Stanciu L.A. Vitamin D modulation of innate immune responses to respiratory viral infections. Rev Med Virol. 2017;27:e1909.

[63] Grant W.B., Lahore H., McDonnell S.L., Baggerly C.A., French C.B., Aliano J.L. Evidence that vitamin D supplementation could reduce risk of influenza and COVID-19 infections and deaths. Nutrients. 2020;12:988.

[64] Huang C., Wang Y., Li X., Ren L., Zhao J., Hu Y. Clinical features of patients infected with 2019 novel coronavirus in Wuhan, China. Lancet. 2020;395:497-506.

[65] Poudel-Tandukar K., Poudel K.C., Jimba M., Kobayashi J., Johnson C.A., Palmer P.H. Serum 25-hydroxyvitamin $\mathrm{d}$ levels and C-reactive protein in persons with human immunodeficiency virus infection. AIDS Res Hum Retroviruses. 2013;29:528-534.

[66] Dancer R.C., Parekh D., Lax S., D’Souza V., Zheng S., Bassford C.R. Vitamin D deficiency contributes directly to the acute respiratory distress syndrome (ARDS) Thorax. 2015;70:617-624.

[67] Autier P., Mullie P., Macacu A., Dragomir M., Boniol M., Coppens K. Effect of vitamin D supplementation on non- skeletal disorders: a systematic review of meta-analyses and randomised trials. Lancet Diabet Endocrinol. 2017;5:986-1004.

[68] Bergman P., Lindh ÅU, Björkhem-Bergman L., Lindh J.D. Vitamin D and respiratory tract infections: a systematic review and meta-analysis of randomized controlled trials. PLoS ONE. 2013;8:e65835.

[69] Hamer M, Kivimäki M, Gale CR, Batty GD. Lifestyle risk factors, inflammatory mechanisms, and COVID-19 hospitalization: A community-based cohort study of 387,109 adults in UK. Brain Behav Immun. 2020;87:184187. doi:10.1016/j.bbi.2020.05.059

[70] Ruiz-Roso MB, de Carvalho Padilha P, MantillaEscalante DC, et al. Covid-19 Confinement and Changes of Adolescent's Dietary Trends in Italy, Spain, Chile, Colombia and Brazil. Nutrients. 2020;12(6):E1807. Published 2020 Jun 17. doi:10.3390/nu12061807

[71] Zhao A, Li Z, Ke Y, et al. Dietary Diversity among Chinese Residents during the COVID-19 Outbreak and Its Associated Factors. Nutrients. 2020;12(6):E1699. Published 2020 Jun 6. doi:10.3390/nu12061699

[72] Ammar A, Brach M, Trabelsi K, et al. Effects of COVID19 Home Confinement on Eating Behaviour and Physical Activity: Results of the ECLB-COVID19 International Online Survey. Nutrients. 2020;12(6):E1583. Published 2020 May 28. doi:10.3390/nu12061583

[73] Gomes M, Figueiredo D, Teixeira L, Poveda V, Paúl C, Santos-Silva A, Costa E. Physical inactivity among older adults across Europe based on the SHARE database. Age Ageing. 2017 Jan 20; 46(1):71-77.

[74] Goethals L, Barth N, Guyot J, Hupin D, Celarier T, Bongue B. Impact of Home Quarantine on Physical Activity Among Older Adults Living at Home During the COVID-19 Pandemic: Qualitative Interview Study. JMIR Aging. 2020;3(1):e19007. Published 2020 May 7. doi:10.2196/19007 